\title{
AS CULTURAS LÚDICAS E TELEVISIVAS NO CONTEXTO ESCOLAR: CAMINHOS E POSSIBILIDADES ATRAVÉS DA MEDIAÇÃO
}

Susana Angelin Furlan', José Milton de Lima², Márcia Regina Canhoto de Lima ${ }^{1}$ Jéssika Naiara da Silva ${ }^{3}$, Adriélli da Silva Souza ${ }^{4}$

Universidade Estadual Paulista - FCT/UNESP. ${ }^{1}$ Curso de Educação Física, Presidente Prudente - SP. ${ }^{2}$ Departamento de Educação, Presidente Prudente - SP. ${ }^{3}$ Mestrado em Educação, Presidente Prudente - SP. ${ }^{4}$ Curso de Pedagogia, Presidente Prudente - SP. E-mail: susana dp@hotmail.com - Conselho Nacional de Desenvolvimento Científico e Tecnológico - (CNPq).

\section{RESUMO}

A presente pesquisa assumiu como objetivos apresentar as manifestações televisivas encontradas durante as atividades lúdicas das crianças e ainda apreender a compreensão que as educadoras têm sobre a ludicidade infantil e como medeiam ou/não aspectos advindo dessas mídias, em uma instituição de Educação Infantil no município de Álvares Machado-SP. A pesquisa teve como suporte teórico a Sociologia da Infância e a Comunicação Social. A metodologia utilizada foi de natureza qualitativa, caracterizando-se como Pesquisa do tipo Etnográfica. Como resultados, percebeu-se que a mídia televisiva se encontra cada vez mais inserida nas falas das crianças, nos artefatos culturais que trazem a escola, e ainda revelam-se nos momentos das brincadeiras, como quando utilizam da televisão como suporte e matéria-prima para sua imaginação. Entende-se que a mídia televisiva não é mediada como poderia e por fim que a ludicidade não é valorizada na instituição, é anteposta a conteúdos advindos de saberes linguísticos e matemáticos.

Palavras-chave: Televisão, crianças, infância, ludicidade, mediação

\section{PLAYFUL AND TELEVISION CULTURES IN THE SCHOOL CONTEXT: PATHWAYS AND POSSIBILITIES THROUGH MEDIATION}

\begin{abstract}
ABSTRAT
This research took over as goals present television demonstrations found during the playful activities of children and even seize the understanding that teachers have about the playfulness of children and how to mediate or aspects from those media, in an institution of early childhood education, Álvares Machado-SP. The research had theoretical support for the sociology of childhood and the media. The methodology used was qualitative in nature, characterized as Ethnographic type lookup. As a result, it was noticed that the television media is increasingly embedded in the lines of children in cultural artifacts that bring to school, and even reveal the moments of banter, as when they use the television as a support and raw material for your imagination. It is understood that the television media is not mediated as could and finally the playfulness is not valued in the institution, is prepended to content from linguistic and mathematical knowledge.
\end{abstract}

Keywords: television, children, childhood, playfulness, mediation 
INTRODUÇÃO

$\mathrm{Na}$ contemporaneidade, observamos que o conceito de infância tem-se modificado, juntamente com o que se tornou o cotidiano da família moderna, ritmo acelerado, mulheres saindo para trabalhar e complementar a renda familiar, diminuição da taxa da natalidade, crianças cada vez mais cedo nas creches, com muitas preocupações e cursos preparatórios, e ainda o maior contato das pessoas com as mídias tecnológicas.

Semelhante à própria infância, a ludicidade sofreu e continua a sofrer alterações na forma, no conteúdo, ainda mais pelo contato com as mídias, percebeu-se transformação do brincar no seu conteúdo, na sua forma de vivência e de significado que as crianças the dão ao decorrer da história. A partir de contribuições de diversos autores percebemos que essa atividade vista por nós, adultos, como secundária é a principal atividade da infância, que viabiliza a compreensão e significações de mundo para a criança, influenciando o seu desenvolvimento de modo individual e social.

Segundo Lima e Lima (2013, p.6), a brincadeira se faz muito importante para as crianças, pois representa um dos primeiros componentes das Culturas da Infância, que são também fator fundamental na "recriação do mundo e na produção das fantasias infantis". Para Sarmento (2003) a brincadeira se faz tão importante para as crianças que entre brincar e fazer coisas sérias para elas, não tem distinção, sendo que o brincar é de fato o que elas fazem de mais sério.

Como destaca Correia (2011), pesquisas realizadas por Wajskop (1995), Kishimoto (2001), Vilela (2007), dentre outros, retratam um cotidiano empobrecido do brincar no contexto escolar. As pesquisas apontaram que os professores não valorizam o brincar nas instituições de Educação infantil, estão focados na aquisição de conteúdos, apresentam uma concepção de crianças sem autonomia, assim como um ritmo impeditivo para o desenrolar das brincadeiras.

Fica evidente que "o brincar e o aprender parecem assumir posições opostas nesse processo." (CORREIA, 2011, p.8). Assim há a exigência que o educador tenha bases teórico práticas consistentes e que haja uma formação continuada em relação a importância do brincar.

Entendemos que a Educação infantil é um espaço de vivências privilegiadas de socialização, onde a criança pode se encontrar com seus pares e viver intensamente essa fase da sua vida, com direito a ludicidade e múltiplas linguagens que precisam ser oferecidas a elas.

A partir da constatação do intenso contato das crianças com as mídias televisivas, nesta fase da vida, buscamos compreender quais as manifestações televisivas que as crianças demonstram durante as suas atividades lúdicas, em contato com seus pares e com os adultos. E, 
ainda, entender qual é a compreensão que as professoras tem sobre a ludicidade e se medeiam a relação com os conteúdos advindos das mídias televisivas.

\section{METODOLOGIA}

Para se realizar uma pesquisa é preciso promover um confronto de dados, evidências, informações coletadas e conhecimento teórico acumulado a respeito dele (LUDKE; ANDRÉ, 2013). Desta maneira, seguindo estes requisitos, estamos investigando os elementos culturais de uma instituição de Educação Infantil no município de Álvares Machado, SP., visando compreender e interpretar os fenômenos sociais com base nas perspectivas dos atores por intermédio do envolvimento e presença semanal da pesquisadora no ambiente escolar.

Para tanto, em busca de elucidar esses objetivos, utilizamos da metodologia qualitativa, que não tem uma dimensão quantificável, mas sim interpretativa. Segundo Richardson (1999, p.6) uma metodologia qualitativa:

[...] pode descrever a complexidade de determinado problema, analisar a interação de certas variáveis, compreender e classificar processos dinâmicos vividos por grupos sociais, contribuir no processo de mudança de determinado grupo e possibilitar, em maior nível de profundidade, o entendimento das particularidades do comportamento dos indivíduos.

Utilizamos da pesquisa do tipo etnográfica, que segundo Ludke e André (2013, p.14) "é a descrição de um sistema de significados culturais de um determinado grupo". Nesse estudo, a principal preocupação como destaca André (2005) é com o significado que têm as ações e os eventos para as pessoas, alguns são expressos diretamente pela linguagem falada, outros são transmitidos por meio de outras manifestações. Desta forma, a observação e os registros se fazem muito importantes para que se consiga atingir os objetivos da pesquisa. Visando a descoberta de novos conceitos, novas relações, novas formas de entendimento da realidade.

O grupo pesquisado foi formado por aproximadamente 200 crianças de 3 a 6 anos, e 8 educadoras de uma instituição de Educação Infantil localizada no município de Álvares MachadoSP.

Em relação aos procedimentos metodológicos, a pesquisa utilizou técnicas de observação, entrevistas, questionários, levantamento bibliográfico e diário de campo. Tal escolha se justifica, pois estas técnicas auxiliam no levantamento de dados que permitem desvelar complexidade do problema (RICHARDSON, 1999). 
As observações aconteceram uma vez por semana, durante todo o período letivo. A pesquisadora acompanhava, em média de cinquenta minutos, as atividades lúdicas das turmas e anotava em diário de campo as relações entre: crianças / adultos e crianças / crianças, ressaltando as atitudes, diálogos e expressões.

A pesquisa por ser feita com crianças e educadoras está apoiada no Protocolo do Comitê de Ética em Pesquisa (CEP): Processo no 71/2009.

\section{RESULTADOS}

A investigação revelou que as crianças fantasiam com os personagens da televisão, dentre os dados, destacamos um fato ocorrido num dia de observação, em que uma das crianças pediu para ser chamado de Ben10, ao invés de seu nome, numa brincadeira com a pesquisadora.

E ainda, quando as crianças ressignificavam brincadeiras já conhecidas, como pega-pega, mas colocavam artefatos culturais nas atividades. Ressalta-se um relato em que uma das crianças emprestou o seu relógio das "Princesas Disney" para que o pegador usasse, transformando a brincadeira e tornando-a mais interessante para os pequenos envolvidos.

Perguntamos em um questionário entregue aos pais, os desenhos que as crianças mais assistem. Para melhor representação da questão, segue um gráfico que está em porcentagem. ${ }^{1}$

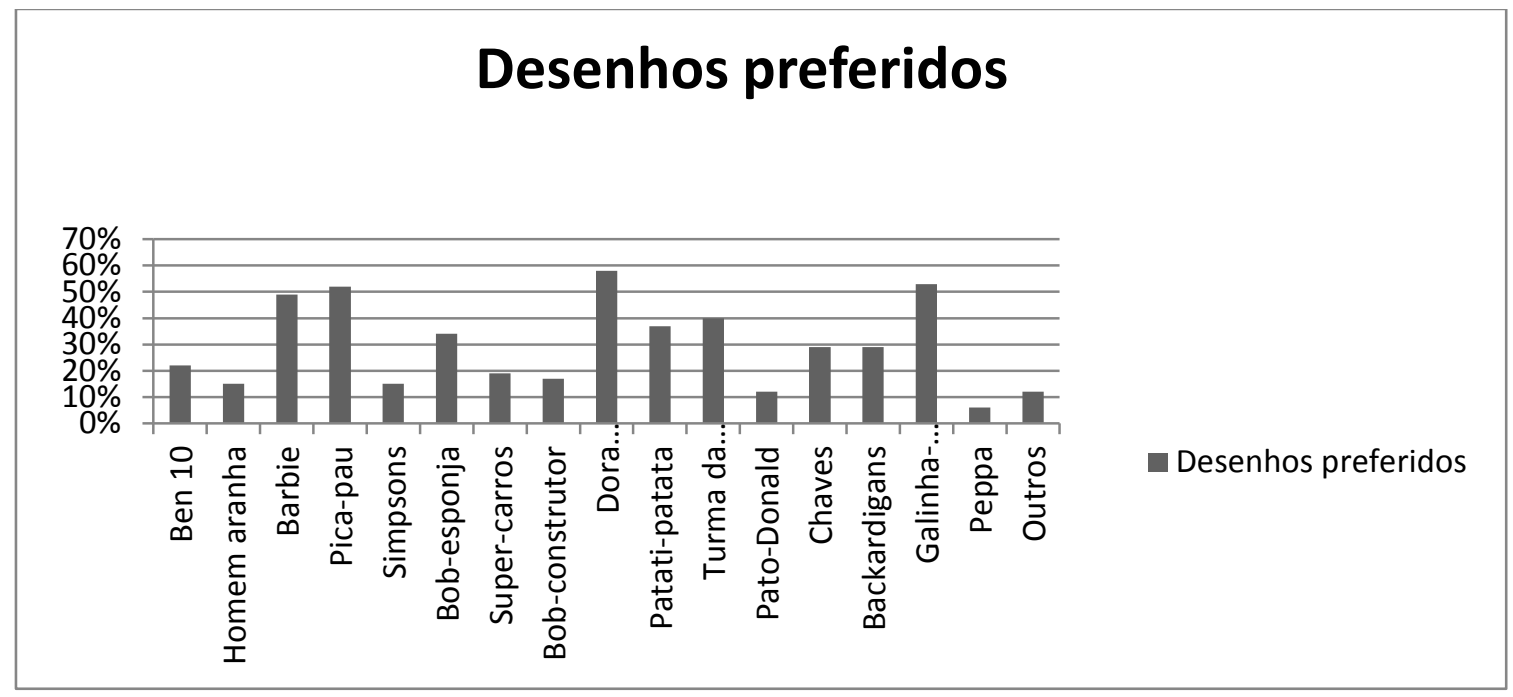

Figura 1. Gráfico com respostas dos responsáveis

Pudemos perceber através deste gráfico que os desenhos mais assistidos pelas crianças da realidade aqui retratada, foram: Dora Aventureira, Galinha-Pintadinha, Pica-pau, Barbie e Super Carros. No geral não são desenhos considerados violentos e nem com programação imprópria

\footnotetext{
${ }^{1}$ Nesta questão podia assinalar mais de uma alternativa, então as porcentagens equivalem quantas vezes essa alternativa foi marcada.
} 
para a idade das crianças investigadas. Sobre os conteúdos que as crianças assistem, os pais relataram que acompanham os filhos no ato de assistir a televisão, mas algumas vezes não compreendem os desenhos ou não conseguem problematiza-los bem.

A respeito do comportamento que os pais devem ter, Lopes, Borelli e Resende (2002, Apud MICHELAN, 2011, p.61), admitem que a família é a principal fonte difusora de cultura. Ressaltam, ainda, que pelo conceito "entende-se por família, como um espaço social, um espaço cultural, e como espaço de mediação das práticas culturais infantis."

Michelan (2011, p.71) traz uma pesquisa de Resende (2002) que verificou que as crianças das famílias que discutiam e comentavam os conteúdos midiáticos nos lares, detinham uma capacidade superior de comunicar informações de forma mais organizada e coerente e assim possuíam um conhecimento mais consistente.

Faz-se relevante destacar a opinião de Fátima, professora da instituição, em entrevista, sobre a relação da criança com a TV, na qual ela descreve um pouco sobre a mediação que entende que deve ser feita em casa:

A relação depende se for mediada eu creio que ela é positiva para a criança, um programa educativa, e tem que ser só um período do dia, não é também porque é um programa educativo que tem que deixar a criança 12 horas em frente a televisão. Elas demonstram que assistem sim, eles comentam até quando descemos pra assistir vídeo, elas falam "na minha casa eu tenho esse, tenho dvd", Esse ano a turminha parece assistir mais desenhos infantis. As meninas brincam bastante de contos de fadas, os meninos montam as armas e brincam de super-heróis, acho que é por conta do que assistem. Eles aparentam assistir mais desenhos animados mesmo. Eu acho que a televisão ajuda no brincar e na imaginação. Justamente porque às vezes acabamos percebendo que sozinhos eles não conseguem brincar, ai precisam mesmo de alguém ou algo para mediar e dar ideias, ai vem a televisão e a importância de um adulto para instruir a brincadeira e a televisão.(Fátima- professora do infantil II).

A maioria das professoras destaca que a relação com a televisão necessita de uma mediação na família, para que esta seja positiva e como as educadoras mesmo disseram: "aumentando a imaginação, a criatividade, enriquecendo o repertório lúdico e por que não, alegrando a criança". Porém muitas delas reclamaram que as crianças demonstram comportamentos violentos e atribuem isso a mídia televisiva.

A respeito do tempo do brincar, a fala de Aparecida, professora do infantil II, reflete a de todas:

É complicado o tempo do brincar, porque na escola temos duas apostilas mais os conteúdos, mais as outras aulas que não estamos com as crianças, como artes, educação física e ai o brincar fica bem restrito, pro final da aula quando eles já 
fizeram todas as atividades e sobrou lá uns 20 minutos, uns 30 minutos que eu vi que não tem mais como dar outra atividade, ai deixo eles brincarem. E esses conteúdos são livres, usando os brinquedos que tem, fazendo de faz de conta, só tenho cuidado de não se machucarem, de não quebrarem brinquedos.(Aparecida-professora Infantil II)

\section{DISCUSSÃO}

Assumimos como uma das bases desta pesquisa a Sociologia da Infância, defendendo que a criança é sujeito social ativo de uma categoria social heterogênea do tipo geracional, essa concepção é contrária ao conceito de simples reprodução do mundo adulto e considera que as crianças realizam a reprodução interpretativa, apreendendo o mundo social como encontram e transformando-o aos seus modos (CORSARO, 2011).

Entendemos também que as contribuições dos adultos são substanciais para o desenvolvimento do hábito lúdico e do senso crítico da criança frente às diversas influências que sofre dos produtos culturais e do contexto social onde está inserida.

Admitindo que a mídia televisiva está cada vez mais inserida no nosso cotidiano, Betti e Lima (2011, p.227) entendem que no momento em que as manifestações televisivas são incorporadas à cultura lúdica das crianças, elas se tornam uma das "instâncias em que as crianças produzem sentidos próprios para os conteúdos televisivos" e a escola, deve valorizar essas instâncias e cabe aos professores, " um "que fazer" ou pelo menos, saber o que não fazer; proibir as brincadeiras!"

Quando falamos de mídias ainda, há a preocupação de ela pode tomar o lugar da imaginação e das brincadeiras e também que ela limite as fantasias. Sobre essa relação destacamos o posicionamento de Girardello (2011), sobre as narrativas que enriquecem a imaginação:

A narrativa da Tv deveria permitir o encontro da criança com alguma dimensão profunda, complexa, misteriosa da vida, mas adequada ao nível de desenvolvimento das crianças. Uma narrativa de qualidade-também na TV- é aquela que oferece metáforas ou continentes para as experiências conscientes ou inconscientes das crianças. Um critério para se avaliar a qualidade de um programa do ponto de vista da imaginação seria ver o que ele oferece para apoiar a necessidade que a criança tem de elaborar suas ansiedades através da fantasia. (Girardello 2011, p. 296)

Levando em conta que os conteúdos televisivos podem alterar o repertório lúdico das crianças, Pereira e Ruaro $(2009$, p.6) destacam que muitas vezes negligenciamos sua carga de 
conteúdos e ideologias específicas de origem religiosa, política, econômica, principalmente a carga cultural que contém.

As autoras entendem que é preciso se construir desde a Educação Infantil o hábito de duvidar de tudo que é dado pela fantasia televisiva. Porém destacam a forte importância na “organização do pensamento infantil através de sua dimensão educativa que se constitui a partir da função de entretenimento desse meio de comunicação." Fazendo com que a televisão seja a sua principal fonte de lazer e dos aspectos lúdicos das mensagens destinadas a elas.

Mesmo a televisão sendo uma das principais fonte de lazer, não se pode deixar que seja a única, visto que como já discutido pelos clássicos (BROUGÈRE, 1998; SARMENTO, 2003), o brincar é muito importante e não é exclusivo das crianças, faz parte da vida humana, representa uma maneira privilegiada "de contato com o outro, o mundo e a cultura. Brincando, as crianças se apoderam criativamente de formas e práticas sociais, aprendendo sobre si mesmas e sobre o mundo em que vivem" (LIMA e LIMA 2013, p.6). Na infância, essa atividade tem uma importante especial devido a compreensão do mundo pelas crianças, desse modo, a brincadeira deve ser valorizada nas escolas, é preciso como destaca Lima e Lima $(2013$, p.8) que os educadores de crianças pequenas compreendam que a cultura lúdica infantil precisa ser expandida. Deve-se ainda "oferecer possibilidade de entendimento, de domínio e de realização de suas próprias brincadeiras, pois é por meio das experiências acumuladas que a criança constrói e amplia sua cultura lúdica"

Portanto conforme apresentado, entendemos que os conteúdos televisivos, quando incorporados ao cotidiano das crianças, podem enriquecer sua fantasia, e seu repertório lúdico da criança. Imperativo também se faz ressaltar a preocupação dada a ludicidade pelas professoras, a fim de que este trabalho possa servir como instrumento para esclarecer a importância desse eixo na cultura das crianças.

\section{CONCLUSÃO}

Em síntese, a presente pesquisa contribuiu para a ampliação da compreensão das culturas lúdicas das crianças em relação às manifestações televisivas. Possibilitou ainda entender o que as professoras pensam sobre a temática e visa contribuir para a discussão sobre a relação mídia e criança.

Com os resultados alcançados pelo estudo, foi possível identificar que as mídias estão sim presentes no cotidiano das crianças, seja dentro do contexto familiar ou no contexto escolar. Essa relação é defendida pelos autores como um contato positivo, porém, pode ser compreendida de 
maneira negativa, quando a mediação que deve ser feita pelos pais/responsáveis, professores e demais adultos não ocorre de forma a analisar, debater e ressignificar os valores, a aprendizagem e os conhecimentos que os conteúdos midiáticos podem proporcionar para os interlocutores.

\section{REFERÊNCIAS}

ANDRÉ, Marli Eliza D.a. Etnografia da prática escolar. Campinas: Papirus, 2005

BROUGÈRE, G. A criança e a cultura lúdica. Revista da Faculdade de Educação, São Paulo, vol.24, n.2., jul/dez, 1998.

BETTI, M; LIMA, J.M;. Cultura lúdica Infantil e Televisão: implicações para a prática educativa. Em: GUIMARÃES, C. M; DI GIORGI, C.A.G,; MENIS, M.S de S. (Org). Os professores e o cotidiano escolar: múltiplos desafios, múltiplos caminhos. Campinas: Mercado das letras. 2011. P.205-234

CORSARO, William A. Sociologia da Infância. 2. ed. Porto Alegre: Artmed, 2011. 384 p.

CORREIA, M.S.A. A brincadeira na perspectiva da Sociologia da Infância: implicações para a Educação Infantil. 2011, disponível em < http://epealufal.com.br/media/anais/426.pdf/> Acesso em 21 abr 2013.

GIRARDELLO, G. Imaginação: arte e ciência na infância. Pro-posições,, Campinas, v. 22, n. 2, p.7592, maio 2011. http://dx.doi.org/10.1590/S0103-73072011000200007

LIMA, J. M. ; LIMA, M. R. Ludicidade como eixo das Culturas da Infância. Interacções. N.27, p207231, 2013

LUDKE, M.; ANDRÉ, M. E. D. A. Pesquisa em Educação: abordagens qualitativas. 2.ed. São Paulo: EPU, 2013

MICHELAN, C. S.; Crianças, consumo e negociação de sentidos: modos de brincar, usos da TV e da internet. São Paulo, 2011. 156 f. Dissertação (Mestrado em Ciências Sociais). Pontifícia Universidade Católica de São Paulo. Disponível em < http://www.sapientia.pucsp.br//tde_busca/arquivo.php?codArquivo=12735> Acesso em: 17 de Set de 2012.

PEREIRA, M. C.; RUARO, L. M. Mídia e desenvolvimento infantil: influências do desenho animado na organização do brincar. 2009. Disponível em: <http://www.pucpr.br/eventos/educere/educere2009/anais/pdf/2062_1398.pdf>. Acesso em: 03 abr 2011.

RICHARDSON, R. J. Pesquisa Social: métodos e técnicas. 2. ed. São Paulo: Atlas, 1999. 